\title{
Designing Supporting Structures of Passenger Ropeways of Minimum Cost Based on Modular Intermediate Towers of Discretely Variable Height
}

\author{
Alexander V. Lagerev' ${ }^{1}$ - Igor A. Lagerev ${ }^{2}$
}

Received: 24 June 2020/Revised: 23 August 2020/ Accepted: 14 September 2020/Published online: 9 November 2020

(C) The Author(s) 2020

\begin{abstract}
Passenger ropeways are a promising alternative for the development of public transport infrastructure in large cities. However, the construction of ropeways has a rather high cost and requires taking into account a significant number of restrictions associated with the features of the existing urban development and the placement of urban infrastructure. The main objective of this research is to develop optimization models that minimize the total cost of modular intermediate towers of a discretely variable height and a rope system due to the optimal placement and selection of the height of these towers, taking into account the features of the surface topography and urban development. The proposed modular principle for the construction of intermediate towers also enables the cost of construction to be further reduced. As a specific example, the design of a ropeway in the city of Bryansk, which has a complex terrain, is considered. The developed models are conveniently used at the initial stage of the design of the ropeway to compare the cost of various options for the location of the ropeway route in order to reduce the risk of error when choosing the least expensive option. The calculation results can serve as a guide for a preliminary assessment of the number and height of intermediate towers, their installation locations on the ground and the characteristics of the cable system.
\end{abstract}

Alexander V. Lagerev

avl-bstu@yandex.ru

1 Institute of Fundamental and Applied Research, Academician I.G. Petrovskii Bryansk State University, Bryansk, Russia 241036

2 Academician I.G. Petrovskii Bryansk State University, Bryansk, Russia 241036

Communicated by Luca D’Acierno.

Keywords Aerial passenger ropeway · Urban environment - Step of towers - Height of towers · Optimization $\cdot$ Cost

\section{List of symbols}

$\alpha_{s l}$

$\psi$

$\psi_{d}$

$\psi_{f}$

\section{$\Delta H_{t}$}

$a, b$

$B_{\mathrm{cab}}$

C

$$
\begin{aligned}
& C_{1 \mathrm{~km}} \\
& C_{e A}, C_{e B}
\end{aligned}
$$

$C_{t}, C_{f}, C_{e}$

$C_{k t}, C_{k n}$

$d_{k t}, d_{k n}$

$d_{k t \max }, d_{k n \max }$

$d_{k t \min }, d_{k n \min }$

$f$
The terrain inclination angle

The coefficient of the tower structure reinforcement

The dynamic factor

The coefficient of permissible sagging between the towers

The constant step of unification

The distance from the adjacent towers to the section of the maximum rope sagging

The length of the passenger cabin

The total cost of intermediate towers and the cable system of the designed ropeway

The cost of $1 \mathrm{~km}$ of the ropeway line The cost the technological equipment mounted at $A$ and $B$ embarkation stations

The unit cost of the tower, the foundation structure and the set of technological equipment

The cost of 1 running meter of the track and carrying rope

The diameters of the track and carrying ropes

The maximum diameters of track and carrying ropes

The minimum diameters of track and carrying ropes

The maximum rope sag 


\begin{tabular}{|c|c|}
\hline$h_{\mathrm{cab}}$ & $\begin{array}{l}\text { The height of the passenger cabin taking } \\
\text { into account the suspension device }\end{array}$ \\
\hline$h_{\min }$ & $\begin{array}{l}\text { The minimum allowable approach of the } \\
\text { bottom of the passenger cabin to the } \\
\text { terrain }\end{array}$ \\
\hline$H_{A}, H_{B}$ & $\begin{array}{l}\text { The height of top towers or embarkation } \\
\text { stations }\end{array}$ \\
\hline$H_{t}$ & The height of the intermediate tower \\
\hline$H_{t \min }, H_{t \max }$ & $\begin{array}{l}\text { The minimum and maximum limiting } \\
\text { height of the intermediate towers }\end{array}$ \\
\hline$I_{t}$ & $\begin{array}{l}\text { The number of intermediate towers } \\
\text { within the designed line }\end{array}$ \\
\hline$l_{k}$ & $\begin{array}{l}\text { The length of the carrying rope between } \\
\text { adjacent towers incl. sagging }\end{array}$ \\
\hline$L_{\mathrm{cab}}$ & The distance between passenger cabins \\
\hline$L_{t}$ & $\begin{array}{l}\text { The distance between two adjacent } \\
\text { intermediate towers }\end{array}$ \\
\hline$L_{t \max }$ & $\begin{array}{l}\text { The limit distance between intermediate } \\
\text { towers }\end{array}$ \\
\hline$L_{t r}$ & The total length of the ropeway \\
\hline$n_{\text {cab }}$ & $\begin{array}{l}\text { The number of passenger cabins within } \\
\text { the same span at the same time }\end{array}$ \\
\hline$[n]_{k}$ & $\begin{array}{l}\text { The minimum rope safety factor } \\
\text { according to the requirements of } \\
\text { regulatory documents on passenger } \\
\text { ropeways safety }\end{array}$ \\
\hline$n_{k n}$ & The number of carrying ropes \\
\hline$n_{t}$ & $\begin{array}{l}\text { The number of intermediate towers } \\
\text { along the line of ropeway }\end{array}$ \\
\hline$q_{\mathrm{cab}}$ & $\begin{array}{l}\text { The distributed load from the weight of } \\
\text { the passenger cabin }\end{array}$ \\
\hline$q_{R k n}$ & $\begin{array}{l}\text { The distributed load on the carrying rope } \\
\text { of the weight of the transported cargo, } \\
\text { wind load and own weight of the rope }\end{array}$ \\
\hline$Q_{\text {cab }}$ & The passenger cabin weight \\
\hline$R_{k n}\left(d_{k n \max }\right)$ & $\begin{array}{l}\text { The breaking force of the carrying rope } \\
\text { of maximum diameter } d_{k n \text { max }}\end{array}$ \\
\hline$S_{k}$ & $\begin{array}{l}\text { The horizontal longitudinal tension } \\
\text { force of the carrying rope }\end{array}$ \\
\hline$T_{k l}, T_{k r}$ & $\begin{array}{l}\text { The axial tension forces of the carrying } \\
\text { rope on adjacent towers }\end{array}$ \\
\hline$u_{i}$ & $\begin{array}{l}\text { The location coordinates of the } i \text { th } \\
\text { intermediate tower along the ropeway } \\
\text { line }\end{array}$ \\
\hline$x_{i}, z_{i}$ & $\begin{array}{l}\text { The } i \text { th variable and invariable } \\
\text { parameters of the optimization problem }\end{array}$ \\
\hline $\begin{array}{l}C_{t 0}, a_{t} \\
C_{f 0}, a_{f}, c_{k t 0}\end{array}$ & $\begin{array}{l}\text { Empirical coefficients obtained from } \\
\text { statistical analysis }\end{array}$ \\
\hline$c_{k t 1}, c_{k t 2}$ & \\
\hline$c_{k n 0}, c_{k n 1}, c_{k n 2}$ & \\
\hline$r_{k t 0}, r_{k t 1}, r_{k t 2}$ & \\
\hline
\end{tabular}

\section{Introduction}

At present, the aerial ropeway is considered as a promising alternative to the development of transport infrastructure in large cities and megacities [1,2], as well as in territorial clusters (for example, tourist or recreational) [3, 4]. This is due to many significant social, technical and economic advantages of this elevated public transport over traditional types-above-ground (trolleybus, bus, tram) and underground (subway) [5, 6]. For urban and natural territories, the environmental aspect of transportation is very important $[7,8]$. Aerial ropeways specifically have very high environmental indicators as they are focused on the use of electric energy, and their construction and operation produce minimal negative impact on the natural terrain. Thus, passenger ropeways have the potential to take a worthy place among other types of modern intelligent transportation systems $[9,10]$.

However, the maximum realization of the potential benefits of ropeways is possible only together with new innovative designs, in particular, those based on mechatronic movement modules and systems for automatic control of the movement of all rolling stock within the transport network of several lines/routes. Schematic solutions and individual design and logistics developments available in this field are presented [11]. Mobile aerial rope systems placed on wheeled or tracked chassis of high carrying capacity and cross-country are also promising [12]. They solve the problem of rapid deployment of the transport system, even in conditions of unequipped and inaccessible territories.

\section{Literature Review}

Of particular importance for scientific research of the problem of introducing passenger aerial ropeways into the transport infrastructure of large cities and territories and its implementation for heterogeneous terrain is the task of rational design of transport lines [11]. Currently, there is sufficient experience in the design and construction of urban aerial ropeways in many countries [13-15]. Cited in a number of works, for example, [7, 16, 17], the data on the required amount of financial resources indicate that the construction of ropeways in real urban conditions is a financially costly undertaking. An additional factor that increases the cost of construction is the need to take into account a significant number of restrictions associated with the features of the existing urban development in plan and height. Obviously, the cost of constructing a specific ropeway depends on many factors - on the location of the line, on the ground in the interval between the terminal 
stations, on the parameters of intermediate tower structures, characteristics of the carrying and traction ropes, etc. [11]. During design, these factors can be manageable within certain limits, thereby managing the cost of ropeway construction. Thus, in modern conditions, the problem of minimizing (optimizing) the cost of ropeway construction is an important practical consideration.

Despite the long-standing need for mathematical methods that enable the designer to solve the problem of optimizing the cost of building passenger ropeways at the design stage, the first studies were only published relatively recently [18, 19]. In [18], as an optimality criterion, it was proposed to use the total cost of intermediate towers, taking into account their total number within the ropeway line and their individual height. In [19], the optimality criterion additionally included the cost of the rope system and foundation structures of intermediate towers. In both papers, it was shown that the optimal choice of the height of the intermediate towers and the tension of the carrying ropes is of paramount importance in managing the cost of constructing a ropeway. These parameters determine the total number and distance between adjacent intermediate towers, as well as the characteristics of the rope system. The above studies were developed in other works by the same authors [20-22]. In particular, the restrictions on the objective functions of the optimization problem were clarified, the influence of the quantitative parameters of the terrain profile along the ropeway line on its optimal cost was investigated, the efficiency of mathematical procedures for solving the optimization problem was increased, etc. The statement of the problem of designing passenger ropeway as a problem of technical and economic optimization, proposed in [21], is a promising approach to solving the practically important problem of minimizing the cost of constructing a ropeway without compromising the reliability and energy efficiency of the technical system.

\section{Statement of the Research Task}

As already noted, the results of technical and economic optimization presented in the works $[20,21]$ show that the cost of optimal variants of passenger aerial ropeways is significantly influenced by the height of intermediate towers. Therefore, the optimal design of the ropeway along the surface with a heterogeneous terrain using available mathematical optimization methods [23] results in the optimal variant requiring the installation of intermediate towers of individual height. In practice, this is an inconvenient circumstance, as the design and production of intermediate towers in this case require an individual approach. Naturally, it complicates and increases the cost of the processes of their design, technological preparation of production, manufacture and installation. Because the construction of the ropeway requires the construction of a large number of intermediate towers (usually from two to five pieces within $1 \mathrm{~km}$ of the ropeway) the problem of unifying the height of intermediate towers remains acute. This unification shall include the use of modular intermediate towers of several standard heights, from the minimum height $H_{t \min }$ to the maximum height $H_{t \max }$. Intermediate standard heights of unified towers in the range $\left(H_{t \min }, H_{t \max }\right)$ differ in height at a constant step of unification $\Delta H_{t}$. The step of unification should also be determined on the basis of feasibility studies.

To solve the technical and economic problem of optimal ropeway design with intermediate towers of discretely variable height, it is advisable to develop and to use two optimization mathematical models:

- Model of optimization of the installation step for modular intermediate towers;

- Model of optimization of the ropeway in general.

The first mathematical model allows one to estimate the optimal characteristics of the ropeway laid mainly along an approximately horizontal or inclined surface of the terrain with an approximately constant angle of inclination $\alpha_{s l}$. Due to the constant geometric shape of the terrain, it is enough to consider a relatively small section of the ropeway - a local area $L_{t}$ between two adjacent intermediate towers of equal height $H_{t}$.

The second mathematical model allows one to estimate the optimal characteristics of the aerial ropeway along its axis taking into account the real heterogeneous terrain. As a rule, significant changes in the geometric shape and quantity indicators of the terrain can be observed along the length of the ropeway. This model is as close as possible to the optimization of real ropeways. Therefore, it should consider the ropeway along its entire length $L_{t r}$. Neighboring unified intermediate towers will typically have different heights $H_{t}$ as multiples of the accepted unification step $\Delta H_{t}$.

\section{Optimization Mathematical Models}

\subsection{Model of Optimization of the Installation Step for Modular Intermediate Towers}

The total cost of intermediate towers of a discretely variable height and the cable system of the designed ropeway consists of the cost of end and intermediate towers, foundation structures under the towers, traction and bearing 
steel ropes, and technological equipment installed on the towers:

$C=n_{t}\left(C_{f}+C_{t}+C_{e}\right)+\left(n_{t}+1\right)\left(C_{k t}+n_{k n} C_{k n}\right) l_{k}$

The values $C_{t}, C_{f}$ included in Eq. (1) must be predetermined for the same type of intermediate towers as a function of their height $H_{t}$. The values $C_{k t}, C_{k n}$ shall also be predetermined for specific grades of steel ropes as a function of their diameter $d_{k t}$ and $d_{k n}$. To obtain empirical regression dependencies $C_{t}\left(H_{t}\right), C_{f}\left(H_{t}\right), C_{k t}\left(d_{k t}\right)$ and $C_{k n}\left(d_{k n}\right)$, the least squares method [24] was used.

Based on the statistical analysis of a large amount of data on the cost of metal intermediate towers of different design and height and the cost of steel ropes for aerial ropeways, the empirical dependencies were suggested (Appendix 1).

The calculation scheme of the mathematical model of the optimization of the installation step for unified intermediate towers of discretely variable height is shown in Fig. 1.

The geometric line of free sagging of the rope between the intermediate towers is a parabola $[25,26]$. Depending on the ratio of the top heights of adjacent intermediate towers and the tension of the carrying ropes $\left(S_{k}\right)$, three shapes of carrying rope sagging can be observed in the span between adjacent towers. These sagging shapes are shown in Fig. 2. For shape I, the section of the largest sagging of the rope is inside the span between the intermediate towers. For shape II, this section is outside the span, and for shape III, this section coincides with one of the span towers. The implementation of a specific shape of sagging rope is determined by the value of the quantitative criterion $K_{f}$

$K_{f}=\frac{q_{R k n} L_{t}}{2 S_{k} \sin \alpha_{s l}}$
Fig. 1 Calculation diagram of the ropeway section between the adjacent intermediate towers

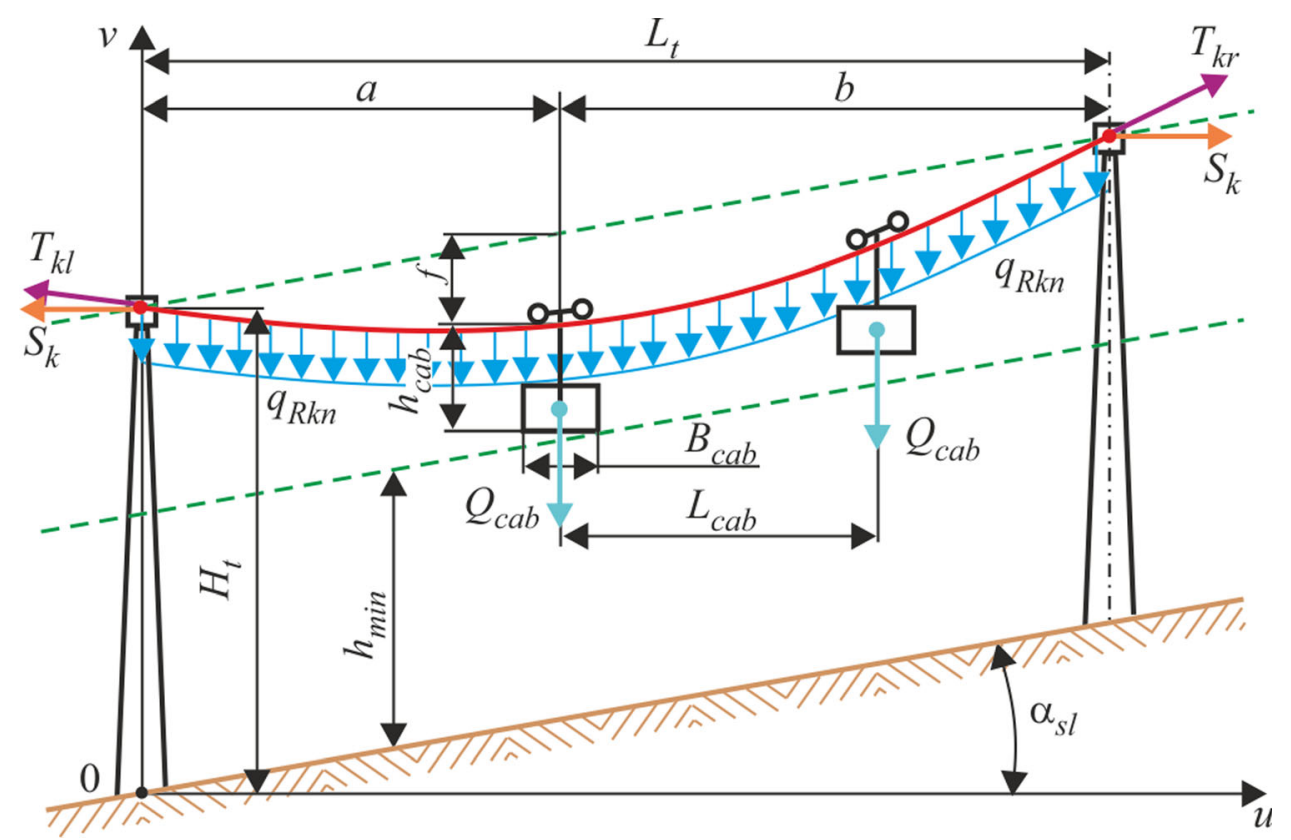

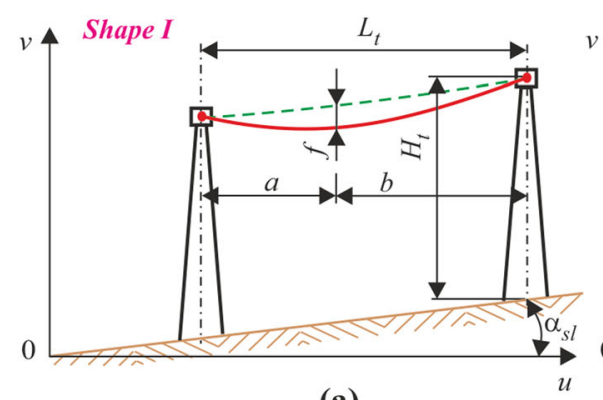

(a)

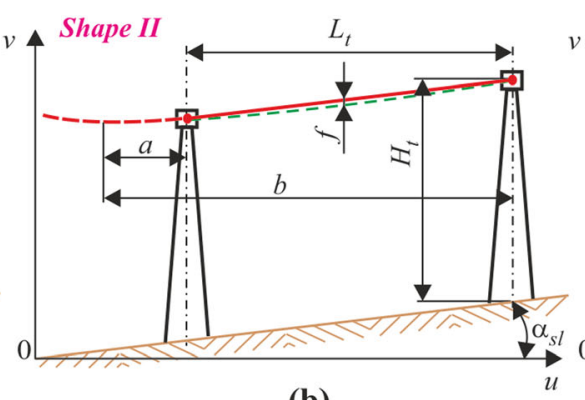

(b)

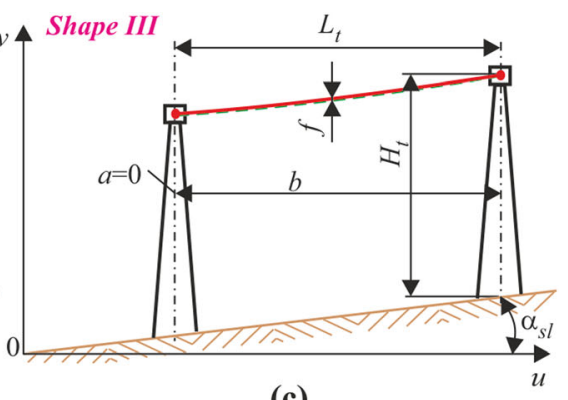

(c)

Fig. 2 Shapes of carrying rope sagging: a shape I, b shape II and $\mathbf{c}$ shape III 
$K_{f}>1$ implements rope sagging under shape I, $K_{f}<1$ under shape II, and $K_{f}=1$ under shape III.

At typical for ropeways values of the rope sagging $f / L_{t}<0.1$ with an error of less than $1.3 \%$ [25], the geometric line of sagging of the carrying rope under shape I can be represented by two sections of the parabola:

$v_{k}\left(0 \leq u \leq L_{t}\right)=\left\{\begin{array}{l}H_{t}-\psi_{d} q_{R k n} u^{2} / S_{k} \quad(0 \leq u \leq a) \\ H_{t}+\psi_{d} q_{R k n} u(u-2 a) / S_{k} \quad\left(a \leq u \leq L_{t}\right)\end{array}\right.$

The geometric line of the sagging of the carrying rope under shapes II and III can be represented by the dependence:

$v_{k}\left(0 \leq u \leq L_{t}\right)=H_{t}+\left[\sin \alpha_{s l}-\psi_{d} \frac{q_{R k n}}{2 S_{k}}\left(L_{t}-u\right)\right] u$

In accordance with the equations in "Appendix 2" (for shape I) and "Appendix 3" (for shape II and III), the typical geometric and power parameters of the ropes can be calculated.

The minimum allowable diameter of the carrying rope which ensures its tensile strength is calculated as the largest of the two values:

$d_{k n}=0.5\left[\sqrt{r_{k 1}^{2}-4 r_{k 2}\left(r_{k 0}-[n]_{k} T_{k l}\right)}-r_{k 1}\right] / r_{k 2}$
$d_{k n}=0.5\left[\sqrt{r_{k 1}^{2}-4 r_{k 2}\left(r_{k 0}-[n]_{k} T_{k r}\right)}-r_{k 1}\right] / r_{k 2}$

It is advisable to form a vector of variable parameters from two independent values of the optimization problem. It is convenient to include the height of intermediate towers $H_{t}$ and the horizontal tension force of the carrying rope $S_{k}$. Therefore, the vector of variable parameters is as follows:

$\{\mathbf{x}\}^{\mathrm{T}}=\left\{x_{1} x_{2}\right\}=\left\{H_{t} S_{k}\right\}$

Such replacement of variable parameters allows one to simplify the procedure for finding the global minimum of the objective function (1), as when it is implemented with the help of one of the direct optimization methods [23], it is possible to use a direct variation of the height of the intermediate towers $H_{t}$ with the accepted unification step $\Delta H_{t}$. This ensures that in the process of searching for the minimum of the objective function, the desired optimal vector of variable parameters $\{\mathbf{x}\}_{\text {opt }}$ will be obtained. The variable $x_{1_{\mathrm{opt}}}=H_{t_{\mathrm{opt}}}$ of this vector will have not an arbitrary value, but a discrete value required by the condition of unifying the height of towers. The installation step of intermediate towers corresponding to the known values $H_{t}$ and $S_{k}$ is determined by the following ratios:
- at carrying rope sagging under shape I between the adjacent towers (if the value of the rope sagging shape criterion $K_{f}>1$ )

$$
\begin{aligned}
L_{t}=\left\{\left[\frac{4 \psi_{d} q_{R k n}}{S_{k}}\left(H_{t}-h_{\mathrm{min}}-h_{\mathrm{cab}}-\frac{\psi_{d} q_{R k n} B_{\mathrm{cab}}^{2}}{4 S_{k}}\right)+\tan ^{2} \alpha_{s l}\right]^{0.5}\right. \\
\left.+\left(\psi_{d}-1\right) \tan \alpha_{s l}\right\} \frac{S_{k}}{\psi_{d} q_{R k n}}
\end{aligned}
$$

- at carrying rope sagging under shapes II and III between the adjacent towers (if the value of the rope sagging shape criterion $K_{f} \leq 1$ )

$$
L_{t}=2\left\{\frac{2 S_{k}}{\psi_{d} q_{R k n}}\left[H_{t}-h_{\mathrm{min}}-h_{\mathrm{cab}}-\frac{B_{\mathrm{cab}}}{2}\left(\frac{\psi_{d} q_{R k n} B_{\mathrm{cab}}}{4 S_{k}}+\tan \alpha_{s l}\right)\right]\right\}^{0.5}
$$

The remaining values used in the mathematical model and for characterizing the geometric dimensions of the ropeway line, operational loads on the carrying ropes, parameters of passenger cabins, etc., are fixed. These values are either specified as input data or calculated according to the specified variable parameters. The first group includes ropeway length $L_{t r}$, distance between adjacent passenger cabins $L_{\text {cab }}$, cabin weight $Q_{\text {cab }}$, minimum allowable approach of the bottom of the passenger cabin to the surface $h_{\min }$, height of the passenger cabin with a suspension device $h_{\text {cab }}$, terrain inclination angle $\alpha_{s l}$, dynamic coefficient $\psi_{d}$, minimum coefficient of rope safety $[n]_{k}$, the carrying rope of maximum diameter $d_{k n \max }$, the breaking force of the carrying rope of maximum diameter of the selected structure $R_{k n}\left(d_{k n \text { max }}\right)$, number of load-carrying $n_{k n}$, ropes and empirical coefficients in regression dependencies (29)-(34). The second group includes: calculated value of the distributed load on one load-carrying rope $q_{R k n}$, distributed load from the weight of the passenger cabin $q_{\text {cab }}$, sagging deflection $f$ and the crosssectional distance of the maximum sagging of the carrying rope from intermediate towers $a$ and $b$, diameters of track $d_{k t}$ and diameters of carrying ropes $d_{k n}$, the distance between two adjacent intermediate towers $L_{t}$, length of carrying rope in span taking into account its sagging $l_{k}$, number of intermediate towers along the ropeway lines $n_{t}$, and axial tension forces of the carrying rope on the left $T_{k l}$ and right $T_{k r}$ towers. The values of the second group form a vector of uncontrollable parameters which are not subject to variation in the process of solving the optimization problem: 


$$
\begin{aligned}
\{\mathbf{z}\}^{\mathrm{T}} & =\left\{z_{1} z_{2} z_{3} z_{4} z_{5} z_{6} z_{7} z_{8} z_{9} z_{10} z_{11} z_{12} z_{13} z_{14}\right\} \\
& =\left[q_{R k n} q_{c a b} f d_{k t} d_{k n} L_{t} l_{k} n_{t} a b T_{k l} T_{k r} \frac{R_{k n}\left(d_{k n \max }\right)}{[n]_{k}} K_{f}\right]
\end{aligned}
$$

Finally, the task of technical and economic optimization of the installation step of intermediate towers of discretely variable height is reduced to the minimization of the objective function (1). Taking into account the Eqs. (29)(34), the optimization task looks as follows:

- in the case of carrying rope sagging between adjacent towers under shape I

$$
\begin{aligned}
O(\{\mathbf{x}\},\{\mathbf{z}\})=\{ & \left.C_{f 0}\left[x_{1}\left(1+\psi \frac{x_{2}}{z_{14}}\right)\right]^{a_{f}}+C_{t 0}\left[x_{1}\left(1+\psi \frac{x_{2}}{z_{14}}\right)\right]^{a_{t}}\right\} \\
& \times\left(\frac{L_{t r}}{z_{6}}-1\right)+\left(C_{k t}+n_{k n} C_{k n}\right) \frac{L_{t r}}{\cos \alpha_{s l}} \\
& \times\left[1+\frac{8}{3}\left(\frac{z_{9} \cos \alpha_{s l}}{z_{6}}\right)^{2}\left(\psi_{d} \frac{z_{1} z_{9}}{x_{2}}+\tan \alpha_{s l}\right)^{2}\right] \rightarrow \min
\end{aligned}
$$

- in the case of carrying rope sagging between adjacent towers under shapes II and III

$$
\begin{aligned}
O(\{\mathbf{x}\},\{\mathbf{z}\})= & \left\{C_{f 0}\left[x_{1}\left(1+\psi \frac{x_{2}}{z_{14}}\right)\right]^{a_{f}}+C_{t 0}\left[x_{1}\left(1+\psi \frac{x_{2}}{z_{14}}\right)\right]^{a_{t}}\right\} \\
& \times\left(\frac{L_{t r}}{z_{6}}-1\right)+\frac{\left(C_{k t}+n_{k n} C_{k n}\right) L_{t r}}{\cos \alpha_{s l}}\left[1+\frac{1}{6}\left(\frac{\psi_{d} z_{1} z_{6}}{2 x_{2} \cos \alpha_{s l}}\right)^{2}\right] \rightarrow \min
\end{aligned}
$$

In this case, the limitations in the form of inequalities that define the following requirements must be met:

- to the height of the limit standard heights of the unified intermediate tower's height

$H_{t \text { max }}-x_{1} \geq 0 ; x_{1}-H_{t \text { min }} \geq 0$

- the minimum height of the intermediate tower at rope sagging under shape I

$$
\begin{aligned}
& x_{1}-h_{\mathrm{min}}-h_{\mathrm{cab}}-\frac{\psi_{d} z_{1} B_{\mathrm{cab}}^{2}}{4 x_{2}} \\
& -z_{9}\left(\psi_{d} \frac{z_{1} z_{9}}{x_{2}}+\tan \alpha_{s l}\right) \geq 0
\end{aligned}
$$

at rope sagging under shapes II and III

$$
\begin{aligned}
x_{1} & -h_{\min }-h_{\mathrm{cab}}-\frac{B_{\mathrm{cab}}}{2}\left(\psi_{d} \frac{z_{1} B_{\mathrm{cab}}}{4 x_{2}}+\tan \alpha_{s l}\right) \\
- & \psi_{d} \frac{z_{1} z_{6}^{2}}{8 x_{2}} \geq 0
\end{aligned}
$$

- to the maximum permissible horizontal tension force of the carrying rope

$z_{14}-x_{2} \geq 0$

- to the allowable range of change of the installation step for adjacent towers

$L_{t \max }-z_{6} \geq 0 ; L_{t r} / z_{6}-1 \geq 0$

- to the allowable range of change of the track rope diameters

$d_{k t \max }-z_{4} \geq 0 ; z_{4}-d_{k t \min } \geq 0$

- to the allowable range of change of carrying rope the diameters

$d_{k n \max }-z_{5} \geq 0 ; z_{5}-d_{k n \min } \geq 0$

- to the maximum allowable sagging of the carrying rope between the towers

at rope sagging under shape I

$\psi_{f} z_{6}-z_{9}\left(\psi_{d} \frac{z_{1} z_{9}}{x_{2}}+\tan \alpha_{s l}\right) \geq 0$

at rope sagging under shapes II and III

$\psi_{f} z_{6}-\psi_{d} \frac{z_{1} z_{6}^{2}}{8 x_{2}} \geq 0$

- to the minimum tension force of the rope according to the requirements of regulatory documents on ropeways safety

at rope sagging under shape I

$x_{2}-\frac{10 n_{\mathrm{cab}} \psi_{d} Q_{\mathrm{cab}}}{n_{k n}} \cos \left[\arctan \left(\psi_{d} \frac{z_{1} z_{9}}{x_{2}}\right)\right] \geq 0$

at rope sagging under shapes II and III

$x_{2}-\frac{10 n_{\mathrm{cab}} \psi_{d} Q_{\mathrm{cab}}}{n_{k n}} \cos \left[\arctan \left(\tan \alpha_{s l}-\psi_{d} \frac{z_{1} z_{6}}{2 x_{2}}\right)\right] \geq 0$

- to the maximum tension force of the rope based on its greatest possible aggregate strength

at rope sagging under shape I 
$z_{14} \cos \left[\arctan \left(\psi_{d} \frac{z_{1}\left(z_{6}-z_{9}\right)}{x_{2}}\right)\right]-x_{2} \geq 0$

at rope sagging under shapes II and III

$z_{14} \cos \left[\arctan \left(\tan \alpha_{s l}+\psi_{d} \frac{z_{1} z_{6}}{2 x_{2}}\right)\right]-x_{2} \geq 0$

To find the minimum of the objective function (11) or (12), taking into account the accepted limitations, one of the direct methods of conditional optimization [23], based on the direct calculation of the value of the objective function $O(\{\mathbf{x}\},\{\mathbf{z}\})$, should be used. Available direct methods (such as Hooke-Jeeves type methods) imply the search for an optimum point $\{\mathbf{x}\}_{\text {opt }}$ by gradually approaching it from the initial optimization point $\{\mathbf{x}\}_{\mathrm{bgn}}$. As it is approached, the search step is gradually reduced until it reaches the desired accuracy of the position of the optimum calculation point within a variety of variable parameters $\{\mathbf{x}\}$. In this case, such a computational algorithm is unacceptable, because for one of the controlled parameters (the height of the intermediate tower $x_{1}=H_{t}$ ), the optimization step should remain constant throughout the whole search for the position of the optimum point and should be equal to the unification step:

$\Delta x_{1}=\Delta H_{t}=$ const.

This requires an appropriate correction of the selected traditional optimization method. It is expected that the minimum cost of ropeway line construction, as determined by the calculation of the objective function (1), will also be influenced by the accepted minimum standard height of the unified intermediate towers with minimum height $H_{t \min }$. This requires a series of optimization calculations for several initial optimization points $\{\mathbf{x}\}_{\text {bgn }}$ that differ in the height of the intermediate tower $\left(x_{1}\right)_{\mathrm{bgn}}=\left(H_{t_{\min }}\right)_{i}$. At the same time, for the $i$ th calculation, the value $\left(H_{t_{\min }}\right)_{i}$ is set in the interval from $H_{t \min }$ to $H_{t \min }+\Delta H_{t}$.

The solution of the problem of optimizing the installation step of unified intermediate towers of discretely variable height taking into account the mentioned features of the computational algorithm of the optimization method was implemented in the "Optimization of the ropeway lines with unified towers" software [27].

\subsection{Model of Ropeway Line Optimization with Modular Unified Towers}

The construction of this optimization model of the cableway with intermediate towers of a discretely variable height required a substantial adjustment to the mathematical model described earlier in [21]. This was because, in the early model, intermediate towers of arbitrary height were considered, and therefore, during the optimization process, it was not possible to provide the necessary discreteness of the tower heights for the optimal solution. The new model is a logical development of the model for optimizing the height and distance between adjacent intermediate towers considered above. It allows one to additionally determine the optimal number of intermediate towers and their optimal location along the line of the ropeway, taking into account the topography and features of the disposition of the urban infrastructure.

Therefore, the vector of variable parameters of the optimization problem contains the heights and coordinates of the location points of the end and intermediate towers:

$$
\begin{aligned}
\{\mathbf{x}\}^{\mathrm{T}} & =\left\{x_{1} x_{2} \ldots x_{n} \ldots x_{N}\right\} \\
& =\left\{H_{A} H_{B} S_{k} u_{1} u_{2} \ldots u_{I_{t}} H_{t 1} H_{t 2} \ldots H_{t I_{t}}\right\}
\end{aligned}
$$

where $H_{A}=H_{t, i=0}, H_{B}=H_{t, i=I_{t}+1}$ are the height of top towers or embarkation stations; $H_{t, i}\left(i \in\left[1, I_{t}\right]\right)$ is the heights of intermediate towers; $u_{i}\left(i \in\left[1, I_{t}\right]\right)$ is the location coordinates of intermediate towers along the ropeway line (where the coordinates of the top towers (embarkation stations) are: for top tower $A: u_{A}=u_{i=0}=0$, for top tower $B: u_{B}=u_{i=I_{t}+1}=L_{t r}$ ).

When searching for the position of the minimum point of the objective function:

$$
\begin{aligned}
\left.O(\{\mathbf{x}\})\right|_{I_{t}=\mathrm{const}}= & C_{t 0 A} x_{1}^{a_{t}}+C_{f 0 A} x_{1}^{a_{f}}+C_{t 0 B} x_{2}^{a_{t}}+C_{f 0 B} x_{2}^{a_{f}}+C_{e A} \\
& +C_{e B}+\sum_{i=1}^{i=I_{t}}\left(C_{t 0 i} a_{i+I_{t}+3}^{a_{i}}+C_{f 0 i} x_{i+I_{t}+3}^{a_{i j}}+C_{e i}\right)+\left(C_{k t}+n_{k n} C_{k n}\right) \\
& \times \sum_{m=1}^{m=I_{t}+1}\left[a_{m}\left(x_{m+I_{t}+2} ; x_{m+I_{t}+3} ; x_{m+2 I_{t}+2} ; x_{m+2 I_{t}+3}\right)\left(1+\psi_{d}^{2} \frac{q_{R k n}^{2} a_{m}^{2}}{6 x_{3}^{2}}\right)\right. \\
& \left.+b_{m}\left(x_{m+I_{t}+2} ; x_{m+I_{t}+3} ; x_{m+2 I_{t}+2} ; x_{m+2 I_{t}+3}\right)\left(1+\psi_{d}^{2} \frac{q_{R k n}^{2} b_{m}^{2}}{6 x_{3}^{2}}\right)\right] \rightarrow \min
\end{aligned}
$$

the condition must be met in which the optimization algorithm provides for a constant step in varying the height of all the end and intermediate towers during the entire process of solving the optimization problem.

The task of optimizing the total cost of the intermediate towers and the rope system (28) is a complex mathematical problem. It has a high dimension due to the fact that for a real ropeway with a length of $5-10 \mathrm{~km}$, the number of variable parameters $N$ in the optimized vector $\{\mathbf{x}\}$ can reach up to 100 unknown values. It is also necessary to consider 11 types of various structural, strength and operational limitations that must be imposed on variables. These limitations are expressed using 99 mathematical dependencies in the form of inequalities. Therefore, the practical implementation of the proposed mathematical model and the problem of minimizing the objective function (28) requires the use of numerical mathematical methods and computer technology. 
The authors developed the computer program "Optimization of the ropeway lines with unified towers" [27]. As a mathematical optimization method, a method of the Hooke-Jeeves type [23] was used. Due to the presence of a large number of constraints and variable parameters, the domain of determination of possible solutions to the optimization problem and the objective function $\left.O(\{x\})\right|_{I_{t}=\text { const }}$ (28) have a very complex form in the $N$-dimensional space of variable quantities. The objective function has several local minima within the domain of determination of possible solutions. When using a computer program, from three to seven local minima of the objective function were recorded. Obviously, only one of these local minima can be considered the best solution to the optimization problem (global minimum). Thus, it is important to correctly set the starting point of optimization $\{\mathbf{x}\}_{\text {bgn }}$-the initial combination of the values of all $N$ variable parameters. In the program "Optimization of the ropeway lines with unified towers," the starting point of optimization is set using the algorithm of sequential enumeration of possible combinations of two variable parameters - the height of the intermediate towers $H_{t}$ (it is assumed to be the same for all supports) and the tension of the carrying ropes $S_{k}$. The parameters $H_{t}$ and $S_{k}$ vary in steps of $\delta H_{t} \sim 10 \mathrm{~m}$ and $\delta S_{k} \sim 40 \mathrm{kN}$ within the intervals of their possible change, respectively. If for the $j$ th starting point $\{\mathbf{x}\}_{j_{\text {bgn }}}$, a possible combination of parameters $H_{t, j}$ and $S_{k, j}$ satisfies the requirements for choosing the starting point (the point should be inside the domain of determination of the optimization problem), then a local minimum of the objective function $\left.O(\{\mathbf{x}\})\right|_{I_{t}=\text { const }}$ (28) is searched using a HookeJeeves type method. From the set of local minima obtained in this way, one point is selected that has the smallest value of the objective function. This point is the point of the global minimum $\left.\{\mathbf{x}\}_{\text {opt }}\right|_{I_{t}=\text { const }}$ and, accordingly, the solution to the optimization problem (28).

The described procedure is performed several times for several arbitrarily set values of the number of intermediate towers along the ropeway line. Comparison of the calculated values of the objective functions $\left.O(\{\mathbf{x}\})\right|_{I_{l}=\text { const }}$ allows one to finally choose the best option for the ropeway, the number of intermediate towers $I_{t}$, and for each $i$ th support, the height $H_{t i}$ and coordinate of the installation location $u_{i}$ along the ropeway line.

To analyze the capabilities of the computer program, design calculations were carried out for promising passenger ropeway lines in the large cities of Rostov-on-Don and Bryansk (Russian Federation). To specify the location and size of the forbidden zones, real maps of these cities were used, and thus the real location of street infrastructure objects and the terrain along the planned lines of ropeways were taken into account. Based on the calculated data, proposals were formulated to develop promising projects for the construction of passenger ropeways in these cities.

\section{Optimal Design Results Analysis}

Calculations were made for a number of possible variants of the aerial passenger ropeway using the computer program "Optimization of the ropeway lines with unified towers" [27]. They have shown that the technical and economic indicators of the optimal variant of installation of unified intermediate towers depend on the step of unification $\Delta H_{t}$, the cost of the tower itself $C_{t}$ and the foundation structures $C_{f}$, the cost of the process equipment $C_{e}$ and the terrain inclination angle $\alpha_{s l}$.

Figure 3 shows the optimization results. These include diagrams of height change and the installation step of unified intermediate towers $H_{t_{\mathrm{opt}}}$ for three unification step values $\Delta H_{t}=2,4$ and $8 \mathrm{~m}$ depending on the terrain inclination angle $\alpha_{s l}$. Structurally, each of these steps can be implemented by means of a special section insert of the corresponding length, attached to the top of the metal structure of the intermediate tower, for example, of the minimum standard height $H_{t \min }$. For the options considered, $\Delta H_{t}$ a single minimum standard height was taken as

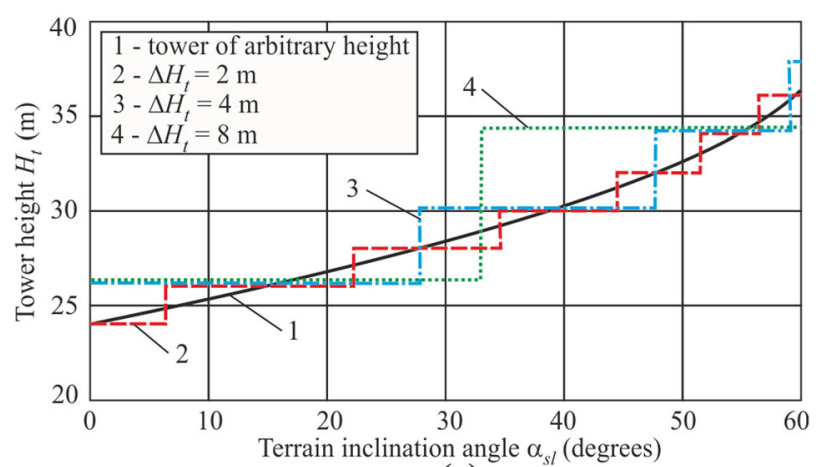

(a)

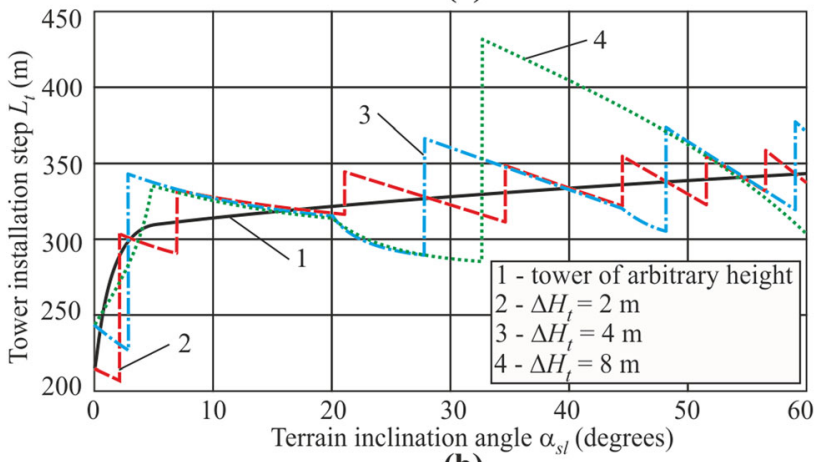

(b)

Fig. 3 The optimal characteristics of the ropeway with unified intermediate towers: a tower height and $\mathbf{b}$ tower installation step 
$H_{t \min }=18 \mathrm{~m}$. Figure 3 also shows a diagram, $H_{t_{\mathrm{opt}}}\left(\alpha_{s l}\right)$, calculated for towers of arbitrary height (non-unified towers) based on solving the problem of technical and economic optimization of the ropeway [11]. For unified towers, the diagram $H_{t_{\mathrm{opt}}}\left(\alpha_{s l}\right)$ has a discrete-step character (Fig. 3a). With the increase of the unification step, $\Delta H_{t}$, the discrepancy increases: the width of the range of angles $\alpha_{s l}$, within which the height of the towers $H_{t_{\mathrm{opt}}}$ is constant, increases.

Changing the installation step of the unified intermediate towers of discretely variable height $L_{t_{\mathrm{opt}}}$ for the optimal variant of the ropeway line depending on the terrain inclination angle $\alpha_{s l}$ also has a discrete-step character (Fig. 3b). Moving to a larger standard height of the unified intermediate tower necessitates the installation of the towers with a larger step, $L_{t_{\text {opt }}}$. Its value then begins to decrease monotonously with further increase of the inclination angle $\alpha_{s l}$ until the transition to a new standard height is required.

This synchronicity of changes in the optimal height and spacing of intermediate towers leads to the fact that the optimal cost characteristics of the ropeway line are expressed not by a discretely graded but by a differentiable function. As an example, Fig. 4 shows a diagram of the cost of $1 \mathrm{~km}$ of the ropeway line $C_{1 \mathrm{~km}}\left(\alpha_{s l}\right)$ for unified towers with a unification step $\Delta H_{t}=8 \mathrm{~m}$. As for cost characteristics of intermediate towers and carrying ropes, the cost characteristics of multifaceted steel towers of PGM500 type and two lay steel ropes under to GOST 3079-80 (Russia) given in [11] were considered. The nonmonotonic character of the diagram $C_{1 \mathrm{~km}}\left(\alpha_{s l}\right)$ is due to the fact that at small terrain inclination angles, $\alpha_{s l} \leq 5^{\circ}$, the sagging curve of carrying ropes for the optimal variant of the ropeway is characterized by shape I. Then, at inclination angles of up to $\alpha_{s l} \sim 6 \ldots 8^{\circ}$, by shape III, and then, by shape II. Analyzing the shape of the diagrams $H_{t_{\mathrm{opt}}}\left(\alpha_{s l}\right)$ in Fig. 4, a, it can be expected that for those angle values $\alpha_{s l}$ at which there is the greatest difference in the heights of unified and non-unified towers, there should also be the largest difference in the cost of $1 \mathrm{~km}$ of the ropeway line.

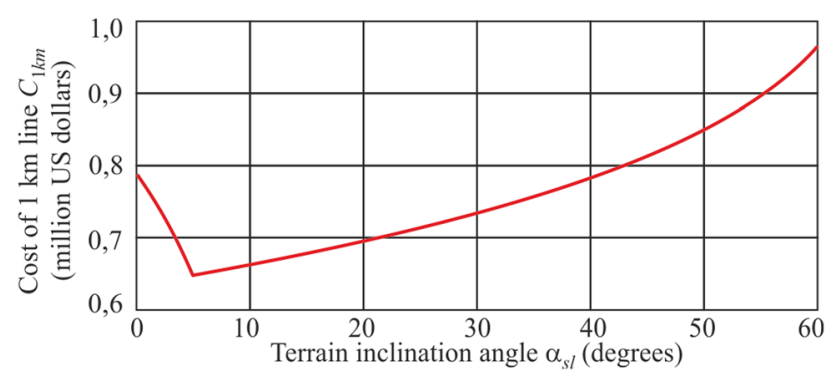

Fig. 4 The cost of $1 \mathrm{~km}$ of the ropeway line for a unified tower with 8-m steps of unification
However, calculations have shown that even with a very large step of unification, $\Delta H_{t}=8 \mathrm{~m}$, the greatest difference in cost is small: it does not exceed $3 \%$, and increases with the increase in the angle $\alpha_{s l}$ and cost of separate towers.

The use of unified intermediate towers of discretely variable height and the unification step has little effect on the optimal value of the horizontal tension load of the carrying ropes $S_{k_{\mathrm{opt}}}$. It is mainly determined by the terrain inclination $\alpha_{s l}$ (Fig. 5). Calculations have shown that the deviation of the value $S_{k_{\mathrm{opt}}}$ for non-unified and unified towers within the range of terrain inclination angles $\alpha_{s l}$ from 0 to $60^{\circ}$ is less than $0.8 \%$.

Numerical study of the influence of the minimum size of unified intermediate towers, $H_{t \min }$, on the optimal characteristics of the ropeway line showed that even with a sufficiently large step of unification, $\Delta H_{t}=8 \mathrm{~m}$, the choice of the minimum standard height within the tower height of up to $8 \mathrm{~m}$ leads to a variety of costs $C_{1 \mathrm{~km}}$ within a small range of $\pm 1.3 \%$, although the deviation $L_{t_{\mathrm{opt}}}$ may reach $\pm 20 \%$.

\section{Best Practices for Using the Optimal Design Results}

The developed optimization mathematical models should be used at the initial stage of designing the lines of aerial passenger ropeways. The analysis of the terrain along the axis of the ropeway allows one to build a height profile for the installation of intermediate towers, to determine the angles of inclination to the horizon of separate sections of this profile and identify the maximum angle $\alpha_{s l_{\max }}$ among them. Optimizing objective functions (11) and (12) for several different angle values $\alpha_{s l}$ in a range from $0^{\circ}$ to $\alpha_{s l_{\max }}$ and the selected unification step $\Delta H_{t}$ allows one to build diagrams $H_{t_{\mathrm{opt}}}\left(\alpha_{s l}\right)$ and $L_{t_{\mathrm{opt}}}\left(\alpha_{s l}\right)$ similar to those shown in Fig. 3. Naturally, when performing these calculations, it is necessary to use the cost parameters $C_{t}, C_{f}, C_{e}, C_{k t}$ and $C_{k n}$ for specific structural types of intermediate towers and ropes which are planned to be used in the ropeway

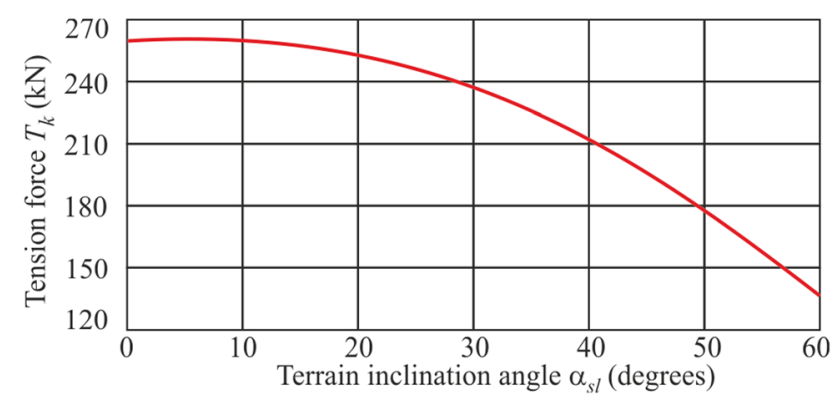

Fig. 5 The horizontal tension force of the carrying ropes for a unified tower with $8-\mathrm{m}$ steps of unification 
construction. Analysis of the obtained diagrams $H_{t_{\mathrm{opt}}}\left(\alpha_{s l}\right)$ and $L_{t_{\mathrm{opt}}}\left(\alpha_{s l}\right)$ allows one:

1. to determine the number of standard height types of unified intermediate towers of different discretely variable height, which should be used in the ropeway construction;

2. to determine the intervals of terrain inclination angles $\alpha_{s l}$ recommended for the installation of specific standard height towers;

3. to determine the step of intermediate towers within the sections of the terrain with approximately the same angle $\alpha_{s l}$;

4. to perform the preliminary design arrangement of intermediate towers along the ropeway axis, taking into account the optimal height and step of unified intermediate towers of discretely variable height.

To clarify the installation location, height and number of intermediate towers, it is advisable to use a mathematical model of ropeway line optimization with unified towers.

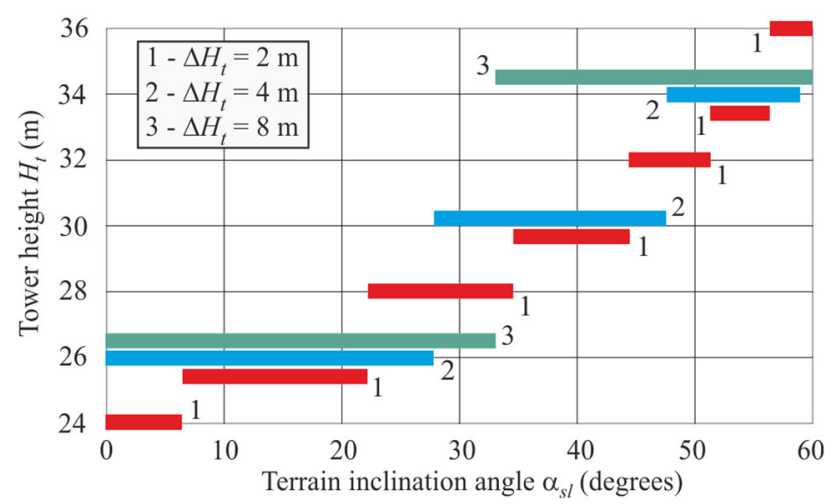

Fig. 6 Intervals of terrain inclination angles recommended for installation of towers of different standard heights using the unification step
Minimization of the objective function (28) further improves the economic performance of the ropeway construction.

As an example, we will consider diagrams $H_{t_{\text {opt }}}\left(\alpha_{s l}\right)$ and $L_{t_{\mathrm{opt}}}\left(\alpha_{s l}\right)$ in Fig. 3, which were obtained for intermediate towers of PGM500 type and two lay steel ropes. The diagram $H_{t_{\mathrm{opt}}}\left(\alpha_{s l}\right)$ analysis shows that at $\left|\alpha_{s l_{\max }}\right|=60^{\circ}$, in the case of using unified towers with a step of unification $\Delta H_{t}=2 \mathrm{~m}$, it is necessary to use seven standard heights $H_{t}: 24,26,28,30$, 32,34 and $36 \mathrm{~m}$. At the unification step, $\Delta H_{t}=4 \mathrm{~m}$, it is necessary to use four standard heights $H_{t}: 26,30,34$ and $38 \mathrm{~m}$. At the unification step, $\Delta H_{t}=8 \mathrm{~m}$, it is necessary to use two standard heights $H_{t}: 26$ and $34 \mathrm{~m}$. The intervals of the terrain inclination angles $\alpha_{s l}$ recommended for the installation of towers of different standard heights for the three unification step values are shown in Fig. 6.

The peculiarities of the proposed approach for the design of passenger ropeway were analyzed during the development of the technical proposal for the construction of the ropeway between two large urban areas of Bryansk City, separated by a wide floodplain of the river Desna. This line is part of the overall concept of erecting six passenger ropeway lines which should form a logistically connected urban extra-street transport ropeway system as a whole [11]. Figure 7 shows the terrain along the axis of the designed ropeway line. It consists of seven sections with an approximately constant length gradient. The absolute value of the angle of the terrain $\left|\alpha_{s l}\right|$ varies from $0^{\circ}$ (Sect. 3) to $36.1^{\circ}$ (Sect. 5).

Figure 7 shows line A of the ropeway that reflects the preliminary design arrangement of intermediate towers along the ropeway axis, taking into account the optimal height and step of the unified intermediate towers of discretely variable height. The installation locations and the height of the unified intermediate towers are determined based on the diagrams $H_{t_{\mathrm{opt}}}\left(\alpha_{s l}\right)$ and $L_{t_{\mathrm{opt}}}\left(\alpha_{s l}\right)$ (Fig. 3). This

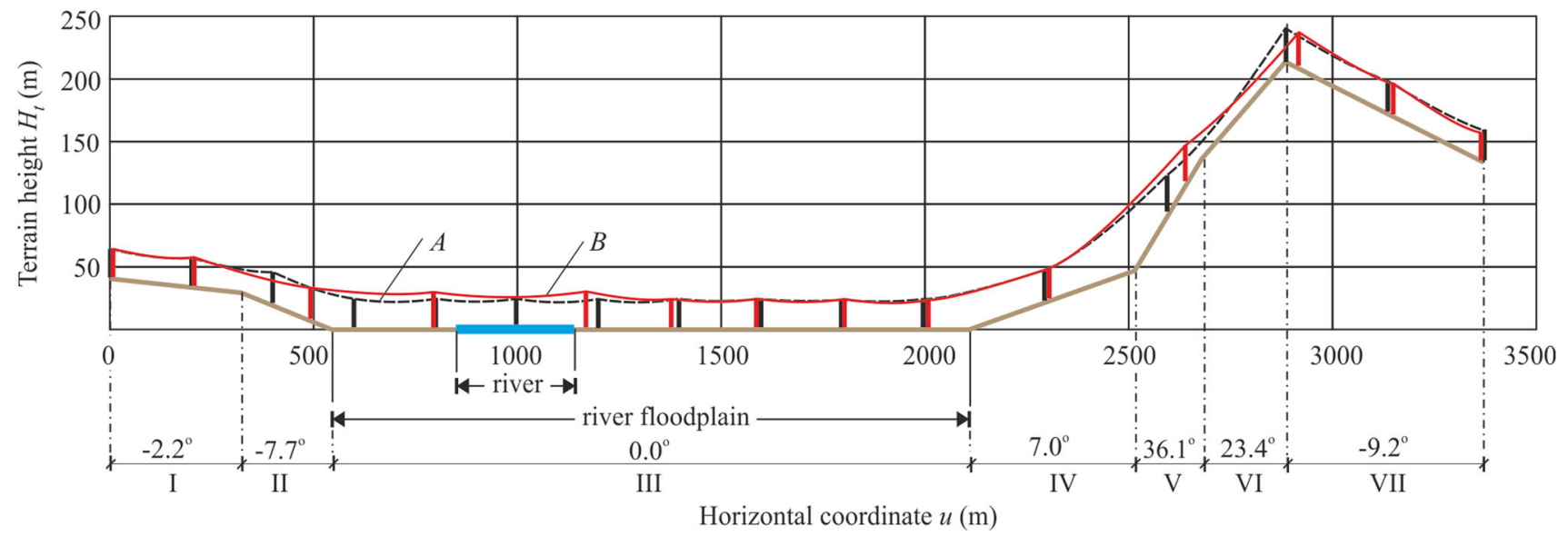

Fig. 7 Variants of ropeway lines in Bryansk City 
line includes 16 top and intermediate towers: 10 towers $24 \mathrm{~m}$ high (they are installed in Sects. 1 and 3), four towers $26 \mathrm{~m}$ high (Sects. 2, 4, 7), one tower $28 \mathrm{~m}$ high (border between Sects. 6 and 7) and one tower $30 \mathrm{~m}$ high (Sect. 5). The cost of the structures and the ropeway system of line A amounted to US $\$ 2.02$ million.

The ropeway line B, shown in Fig. 7, is an improved version of line A. The clarification of the installation locations and height of the unified intermediate towers of line A was performed using calculations according to the ropeway optimization model as a whole. Line B includes 14 top and intermediate towers: seven towers $24 \mathrm{~m}$ high (they are installed in Sects. 1 and 3 and in the end of Sect. 7), three towers $26 \mathrm{~m}$ high (Sects. 2, 4 and 7), one tower $28 \mathrm{~m}$ high (at the beginning of Sect. 7) and three towers $30 \mathrm{~m}$ high (Sects. 3 and 5). The increase in the number of intermediate towers of $30 \mathrm{~m}$ height (three towers instead of one tower) is due to the fact that the calculation of the ropeway line optimization model took into account the restriction prohibiting the installation of an intermediate tower in the riverbed. The application of this restriction is based on the obvious fact that the installation of a tower in the riverbed significantly increases the cost of construction and installation, although it has little effect on the cost of the metal structure of the tower itself. The results of the optimal calculation showed that two additional 30-m-high towers should be installed along the banks of the river and thus extend the span over the river. The cost of the structures and the ropeway system of line B amounted to US $\$ 1.89$ million.

Thus, additional structure cost minimization for the designed ropeway enabled a reduction of about $6.2 \%$. This results in two conclusions:

1. The identification of installation locations and height of unified intermediate towers based on optimization calculations obtained using the optimization model of the installation step for intermediate towers enables the creation of a ropeway design whose cost is close to the lowest possible value;

2. The procedure for further clarification of installation locations and the height of unified intermediate towers using the optimization model of ropeway line with unified towers is desirable, as it allows for additional minimization of the cost and provides additional economic benefits.

\section{Conclusion}

The mathematical models developed in this article for determining the basic structural parameters of intermediate towers (height of towers and distances between adjacent towers) can minimize the cost of supporting structures and the cable system of passenger ropeways taking into account the real surface topography. They are universal in nature and can be used in the design of ropeways in any environmental conditions of different countries.

The developed design method for passenger aerial ropeways, based on minimizing the construction cost, can be recommended for use at the initial stage of their design. It is advisable to use the method when analyzing the following design situations:

- the location of the ropeway line on the ground has already been pre-selected;

- the location of the ropeway line on the ground has not yet been pre-selected, and the designer is considering several alternative options.

When analyzing the first design situation, the calculation results allow the designer to make a preliminary assessment of the number and size of intermediate towers, their installation locations on the ground and the characteristics of the rope system. The use of these results in the further development of the revised construction project gives the designer a certain guarantee that the cost of building the ropeway will be close to the minimum possible, based on the quantitative parameters of the terrain and the features of the location of urban infrastructure facilities. The optimal disposition of the intermediate towers also helps to reduce the required volume of building work and materials. When analyzing the second design situation, the results of calculations carried out for each alternative location of the ropeway line can be used to compare these options and select the most favorable option based on the criterion of the minimum construction cost. This reduces the risk of errors when choosing the most favorable option for laying the line of the projected ropeway.

The use of unified intermediate towers of discretely variable height is an effective technological measure that significantly increases the manufacturability of aerial passenger ropeways. This approach allows the designer to implement a modular principle of manufacturing intermediate towers: the arbitrary tower of the ropeway is constructed as a combination of the lower metal structure of standard height type $H_{t \text { min }}$ and several modular metal structures of the same length $\Delta H_{t}$. Thus, the installation of the intermediate tower for the ropeway consists of two stages:

Stage 1: the lower metal structure of standard height type $H_{t \min }$ is installed and fixed on the foundation.

Stage 2: the standard-height tower is increased to the required height $H_{t}$ by the sequential installation of one or more modular height inserts on the top of the standardheight tower $\Delta H_{t}$.

The modular approach enables a reduction in the range of building steel structures, as only two structures are 
actually required - a standard-height metal structure and a modular metal structure as an insert. This increases the efficiency of production preparation, the production itself and the installation of intermediate towers.

The economic effect of using this modular approach is that it makes it easy to implement optimal structural parameters of the ropeway $H_{t_{\mathrm{opt}}}\left(\alpha_{s l}\right)$ and $L_{t_{\mathrm{opt}}}\left(\alpha_{s l}\right)$ under the conditions of complex heterogeneous elevation of terrain along the axis of the ropeway. A complex terrain requires the installation of intermediate towers with variable step and variable height on ropeway sections depending on the angle $\alpha_{s l}$ of those sections. Optimal design parameters guarantee the minimum cost of construction of aerial passenger ropeways compared to other alternative locations of intermediate towers along the ropeway axis.

Acknowledgements The study was supported by President Grant for Government Support of Young Russian Scientists No. MD422.2020.8.

Author's Contribution All authors contributed to the study conception and design. Material preparation, data collection and analysis were performed by AVL and IAL. IAL performed the simulation. The first draft of the manuscript was written by AVL, and all authors commented on previous versions of the manuscript. All authors read and approved the final manuscript.

Data Availability Some or all data, models or code generated or used during the study are available from the corresponding author by request.

\section{Compliance with Ethical Standards}

Conflict of interest The authors declare that they have no conflict of interest.

Open Access This article is licensed under a Creative Commons Attribution 4.0 International License, which permits use, sharing, adaptation, distribution and reproduction in any medium or format, as long as you give appropriate credit to the original author(s) and the source, provide a link to the Creative Commons licence, and indicate if changes were made. The images or other third party material in this article are included in the article's Creative Commons licence, unless indicated otherwise in a credit line to the material. If material is not included in the article's Creative Commons licence and your intended use is not permitted by statutory regulation or exceeds the permitted use, you will need to obtain permission directly from the copyright holder. To view a copy of this licence, visit http://creativecommons. org/licenses/by/4.0/.

\section{Appendix 1}

Cost of an intermediate tower with the height of $H_{t}$

$C_{t}=C_{t 0} H_{t}^{a_{t}}, \quad\left(H_{t \min } \leq H_{t} \leq H_{t \max }\right)$

Cost of foundation structures for intermediate tower
$C_{f}=C_{f 0} H_{t}^{a_{f}}, \quad\left(H_{t \min } \leq H_{t} \leq H_{t \max }\right)$

Cost of 1 running meter of track rope

$C_{k t}=c_{k t 0}+c_{k t 1} d_{k t}+c_{k t 2} d_{k t}^{2}, \quad\left(d_{k t \min } \leq d_{k t} \leq d_{k t \max }\right)$

Cost of 1 running meter of carrying rope

$C_{k n}=c_{k n 0}+c_{k n 1} d_{k n t}+r_{k n 2} d_{k n}^{2}, \quad\left(d_{k n \min } \leq d_{k n} \leq d_{k n \max }\right)$

The breaking force of track rope

$R_{k t}=r_{k t 0}+r_{k t 1} d_{k t}+r_{k t 2} d_{k t}^{2}, \quad\left(d_{k t \min } \leq d_{k t} \leq d_{k t \max }\right)$

The breaking force of carrying rope

$R_{k n}=r_{k n 0}+r_{k n 1} d_{k}+r_{k n 2} d_{k}^{2}, \quad\left(d_{k n \min } \leq d_{k n} \leq d_{k n \max }\right)$

\section{Appendix 2}

Maximum sagging deflection (Fig. 2)

$f=a\left(\psi_{d} \frac{q_{R k n} a}{2 S_{k}}+\sin \alpha_{s l}\right)$

The distance from the adjacent towers to the section of the maximum rope sagging (Fig. 2)

$a=\frac{1}{2}\left(L_{t}-\frac{2 S_{k}}{q_{R k n}} \sin \alpha_{s l}\right)$

$b=\frac{1}{2}\left(L_{t}+\frac{2 S_{k}}{q_{R k n}} \sin \alpha_{s l}\right)$

The length of the carrying rope in the span between the towers

$l_{k} \approx a\left(1+\psi_{d}^{2} \frac{q_{R k n}^{2} a^{2}}{24 S_{k}^{2}}\right)+b\left(1+\psi_{d}^{2} \frac{q_{R k n}^{2} b^{2}}{24 S_{k}^{2}}\right)$

The axial tension forces of the carrying rope on adjacent towers

$T_{k l}=S_{k} / \cos \left[\arctan \left(\psi_{d} q_{R k n} a / S_{k}\right)\right]$
$T_{k r}=S_{k} / \cos \left[\arctan \left(\psi_{d} q_{R k n} b / S_{k}\right)\right]$

\section{Appendix 3}

Maximum sagging deflection (Fig. 2)

$f=\psi_{d} \frac{q_{R k n} L_{t}}{8 S_{k}}$

The distance from the adjacent towers to the section of the maximum rope sagging (Fig. 2) 
$a=b=0.5 L_{t}$

The length of the carrying rope in the span between the towers

$l_{k} \approx L_{t}\left(+\psi_{d}^{2} \frac{q_{R k n}^{2} L_{t}^{2}}{24 S_{k}^{2}}\right)$.

The axial tension forces of the carrying rope on adjacent towers

$$
\begin{aligned}
& T_{k l}=S_{k} / \cos \left[\arctan \left(\sin \alpha_{s l}-0.5 \psi_{d} q_{R k n} L_{t} / S_{k}\right)\right] \\
& T_{k l}=S_{k} / \cos \left[\arctan \left(\sin \alpha_{s l}+0.5 \psi_{d} q_{R k n} L_{t} / S_{k}\right)\right]
\end{aligned}
$$

\section{References}

1. Vuchic V (2007) Urban transit systems and technology. Wiley, Hoboken

2. Garsous G, Suárez-Alemán A, Serebrisky T (2017) Cable cars in urban transport: travel time savings from La Paz-El Alto (Bolivia). Transport Policy. Banco Inter-Americano de Desarrollo, Washington, DC. https://doi.org/10.1016/j.tranpol.2017.05.005

3. Hoffmann K (2006) Recent developments in cable-drawn urban transport systems. FME Trans 34:205-212

4. Nikšić M, Gašparović S (2010) Geographic and traffic aspects of possibilities for implementing ropeway systems in passenger transport. Promet Traffic Trans 22(5):389-398. https://doi.org/10. 7307/ptt.v22i5.204

5. Escobar-García D, García-Orozco F, Cadena-Gaitán C (2013) Political determinants and impact analysis of using a cable system as a complement to an urban transport system. Maastricht University UNU-MERIT Working Paper Series: 2013-017

6. Tiessler M, Engelhardt R, Bogenberger R, Hessel C, SerwaKlamouri $M$ (2019) Integration of an urban ropeway into Munich's transit system demand modeling. Transp Res Rec 2673(10):47-57. https://doi.org/10.1177/0361198119844760

7. El-Jouzou H (2016) A comparative study of aerial ropeway transit (ART) systems. Advantages and possibilities. A thesis of Master of Sciences. Frankfurt University of Applied Sciences Master Dissertation

8. Beňo P, Krilek J, Kováč J, Kozak D, Fragassa C (2018) The analysis of the new conception transportation cableway system based on the tractor equipment. FME Trans 46:17-22. https://doi. org/10.5937/fmet1801017B

9. Mohan D (2009) Intelligent transportation systems (ITS) and the transportation system. UNESCO-Encyclopedia Life Support Systems. http://greenplanet.eolss.net/EolssLogn/LoginForm.aspx. Accessed 26 June 2007

10. Winter JA, Sesma I, Funda M (2016) Case study of cable-propelled transit to be an alternative application to conventional means of public transportation. In: 15th International conference on automated people movers and automated transit systems 2016: innovation in a rapidly urbanizing world, Toronto, Canada. https://doi.org/10.1061/9780784479797.025

11. Korotkiy AA, Lagerev AV, Meskhi BC, Lagerev IA, Panfilov AV (2017) The development of transport infrastructure of large cities and territories on the basis of technology of passenger ropeways. DGTU, Rostov-on-Don. https://doi.org/10.5281/zenodo.1311913
12. Tarichko VI, Khimich AV (2019) Comprehensive model of the mobile transport and overloading rope complex. Nauchnotekhnicheskiy vestnik Bryanskogo gosudarstvennogo universiteta 4:523-532. https://doi.org/10.22281/2413-9920-2019-05-04-523532

13. Chu N. (2012) Overview of urban gondolas: implications and opportunities for implementation in Chinese cities. In: Proceedings of 12th COTA international conference of transportation professionals. Beijing, China. https://doi.org/10.1061/ 9780784412442.342

14. Alshalalfah B, Shalaby A, Dale S (2014) Experiences with aerial ropeway transportation systems in the urban environment. J Urban Plan Dev 140(1):04013001. https://doi.org/10.1061/ (ASCE)UP.1943-5444.0000158

15. Nuessgen M (2015) Urban ropeways in Europe. Creating opportunities in urban development. Eurist-European Institute for Sustainable Transport, pp 1-27. https://doi.org/10.13140/RG.2.1. 1446.2163

16. Lagerev AV, Lagerev IA (2017) Prospects of introduction of innovative technology overhead passenger traffic on the basis of the passenger ropeways for the modernization of the public transport system of the Bryansk city. Nauchno-tekhnicheskiy vestnik Bryanskogo gosudarstvennogo universiteta 2:163-177. https://doi.org/10.22281/2413-9920-2017-03-02-163-177

17. Metro de Medellin. https://www.metrodemedellin.gov.co/. Accessed 22 Aug 2020

18. Thaler H, Wenin M, Brunner J, Reiterer D, Bertotti ML, Modanese G, Oberhuber E (2015) Numerical optimization in cable railway planning. In: Proceedings of 9th international conference on advanced computational engineering and experimenting. Springer, Munich

19. Lagerev AV, Lagerev IA (2014) Optimizing the step of installation of intermediate tower structures along the ropeway line. Vestnik Bryanskogo gosudarstvennogo universiteta 4:22-30. https://doi.org/10.5281/zenodo.1302237

20. Thaler H, Wenin M, Brunner J, Reiterer D, Bertotti ML, Modanese G, Oberhuber E (2017) Numerical optimization in ropeway planning. In: Properties and characterization of modern materials. Advanced structured materials. Springer, Singapore. https://doi. org/10.1007/978-981-10-1602-8_10

21. Lagerev AV, Lagerev IA (2019) Design of passenger aerial ropeway for urban environment. Urban Rail Transit 5(1):17-28. https://doi.org/10.1007/s40864-018-0099-z

22. Lagerev AV, Lagerev IA, Tarichko VI (2019) Impact of design capacity on optimal parameters of freight aerial mono-cable cableways. In: International conference on innovations and prospects of development of mining machinery and electrical engineering, IOP conference series: earth and environmental science, Saint-Petersburg, Russia. https://doi.org/10.1088/1755-1315/378/ $1 / 01206312$

23. Reklaitis GV, Ravindran A, Ragsdell KM (1983) Engineering optimization. Methods and applications. Wiley, New York

24. Molugaram K, Rao GS (2017) Curve fitting. In: Statistical techniques for transportation engineering. Butterworth-Heinemann, Oxford. https://doi.org/10.1016/B978-0-12-811555-8.00005-2

25. Birger IA, Shorr BF, Shneyderovich RM (1966) Strength calculation of machine parts. Mashinostroenie, Moscow

26. Szabo I (1987) Geschichte der mechanischen Prinzipien. Birkhäuser, Basel

27. Lagerev AV, Lagerev IA (2017) Optimization of the ropeway lines with unified towers. The Certificate No. 2017662165 on official registration of the computer program (RU). https://doi. org/10.5281/zenodo.3552924 